\title{
Legal Education Review
}

Volume 18 | Issue 1

Article 7

$1-1-2008$

\section{Lawyer Dissatisfaction, Emotional Intelligence and Clinical Legal Education}

Colin James

University of Newcastle

Follow this and additional works at: https://epublications.bond.edu.au/ler

Part of the Legal Education Commons

\section{Recommended Citation}

James, Colin (2008) "Lawyer Dissatisfaction, Emotional Intelligence and Clinical Legal Education," Legal Education Review: Vol. 18 : Iss. 1 , Article 7.

Available at: https://epublications.bond.edu.au/ler/vol18/iss1/7

This Article is brought to you by the Faculty of Law at ePublications@bond. It has been accepted for inclusion in Legal Education Review by an authorized administrator of ePublications@bond. For more information, please contact Bond University's Repository Coordinator. 


\section{LAWYER DISSATISFACTION, EMOTIONAL INTELLIGENCE AND CLINICAL LEGAL EDUCATION}

COLIN JAMES

\section{INTRODUCTION}

This article reports on research at the University of Newcastle, Australia, in 2006, which sought to identify the major causes of stress and dissatisfaction among lawyers and to correlate that information with measures of lawyers' mental wellbeing (neuroticism), emotional intelligence, and the type of legal education and practical legal training (PLT) they had received. Part II reviews the relevant literature, Part III outlines the methodology, Part IV the findings, and Part $\mathrm{V}$ the recommendations.

\section{LITERATURE REVIEW}

The wellbeing of lawyers in the United States has been a concern in the profession since at least 1990. ${ }^{1}$ The American Bar Association conducted a survey of lawyers of all ages and its report, At the Breaking Point, found lawyers' mental health and quality of life declined significantly from 1984 to $1990 .^{2}$ Subsequently, other researchers have published reports on 'unhappiness' in the

Solicitor, University of Newcastle Legal Centre and Senior Lecturer, University of Newcastle School of Law.

1 G Andrew Benjamin, Elaine Darling and Bruce Sales, 'The Prevalence of Depression, Alcohol Abuse and Cocaine Abuse Among United States Lawyers' (1990) 13 International Journal of Law and Psychiatry, 233, 240-1. William W Eaton, James C Anthony, Wallace Mandel and Roberta Garrison, 'Occupations and the Prevalence of Major Depressive Disorder' (1990) 32 Journal of Occupational Medicine 1079, 1081-3; Susan Daicoff, 'Lawyers As the Walking Wounded' (2006) 2(4) The Complete Lawyer 4; Martin E P Seligman, Paul R Verkuil and Terry H Kang, 'Why Lawyers Are Unhappy' (2005) 10 Deakin Law Review 1, 49; Carol Langford, 'Depression, Substance Abuse and Intellectual Property Lawyers' (2005) 53 University of Kansas Law Review 875.

2 American Bar Association, At the Breaking Point: The Report of A National Conference on the Emerging Crisis in the Quality of Lawyers' Health and Lives - Its Impact on Law firms and Client Services (1991). 
legal profession and professional groups have instituted programs designed to improve lawyers' 'quality of life'. ${ }^{3}$

One researcher speculated that the decline in lawyer satisfaction and mental health is only one aspect of a 'tripartite crisis' currently afflicting lawyers. The other two issues of concern are the decline in professionalism and the decline in the public perception of lawyers. ${ }^{4}$

In Australia, studies by the Law Society of New South Wales from 2001 to 2004 show that up to 18 per cent of responding solicitors were dissatisfied or very dissatisfied with their jobs. ${ }^{5}$ In 2004, 52 per cent indicated that stress at work had increased over the previous 12 months and about a third reported discrimination, harassment, intimidation or bullying. Many reported an intention to leave the profession; a Law Society survey in 2005 found that more than one quarter of lawyers in New South Wales intended to leave the profession, and the most common reason was 'lifestyle'. ${ }^{6}$

There is evidence to suggest Australian law firms are becoming more 'Americanised' due to globalisation, increasing competition and strict billing expectations on lawyers in large firms, raising the potential for work-related stress. In Victoria, the Law Institute Journal observed, in 2003, that many Australian law firms invest substantially in developing firm-specific skills in lawyers, yet fail to retain high-potential employees in the long term. ${ }^{7}$

There are also high rates of mobility among lawyers, which seems to be a growing problem for law firms, and evidence of a large proportion of lawyers leaving the profession. ${ }^{8}$ Those findings suggest low levels of satisfaction among lawyers but give little insight into

3 New York City Bar, Report of the Taskforce on Lawyers' Quality of Life (2000) 55 Record of the Association of the Bar of the City of New York 755, $756<\mathrm{http} / /$ tinyurl.com/5t6d33> at 7 December 2008; similar reports from other American states are published on the New York Bar Association website $<$ http://tinyurl.com/565tlp $>$ at 7 December 2008.

4 Susan Daicoff, 'Lawyer, Know Thyself: A Review of Empirical Research on Attorney Attributes Bearing on Professionalism' (1997) 46 American University Law Review 1337, 1361-2.

5 Law Society of New South Wales, Remuneration and Work Conditions Report (2001-04). See also Beaton Consulting, The Annual Professions Study 2007: Short Report (2007).

6 Law Society of New South Wales, Remuneration and Work Conditions Report (2005). See also Sharon Drummond, 'Legal Start Salaries Among the Highest' Lawyers Weekly http://www.lawyersweekly.com.au/articles/Legalstart-salaries-among-highest_z67772.htm> at 7 December 2008.

7 Olivia Prodan, 'Turn and Türn About: Employee Turnover in Legal Firms Can Be Predicted and Steps Taken to Avert This Loss of Human Capital' (2003) 77(4) Law Institute Journal 90; John Quinlan, 'Human Resources: Minding the Family' (2003) 77(12) Law Institute of Journal 96.

8 Victorian Women Lawyers Association, 'Taking Up the Challenge: Women in the Legal Profession' (1999) Law Institute Journal 19; Lucinda Schmidt, 'Law is Hell', Business Review Weekly (Melbourne), 29 September 2000, 70; Matthew Coghlan, 'Young Lawyers Rebel Against Billable Hours', Australian Financial Review (Sydney), 4 August 2006, 1, 57. 
the causes of discontent. It is unclear, for example, whether lawyers are dissatisfied with the nature of legal practice itself or their specific job, and whether their dissatisfaction is related to their legal education and training, their workplace conditions, personality issues or a combination of factors. Understanding the causes of dissatisfaction among lawyers may help the profession and, ultimately, benefit all stakeholders including not only lawyers themselves, but their employers, courts, clients and the general community.

\section{Methodology}

This project was conducted in 2006 and involved an online survey and telephone interviews of graduates of the School of Law at the University of Newcastle between 1997 and 2004. The aims of the study were:

- to assess and compare levels of workplace satisfaction of lawyers with the type of undergraduate education they experienced at law school;

- to identify the major causes of stress and dissatisfaction among lawyers and determine whether they are internal (related more to the lawyer) or external (related more to the workplace);

- to provide feedback to course designers, including School of Law staff and legal practitioners at University of Newcastle Legal Centre (UNLC) who supervise students in the Professional Program; and

- to identify correlations between the emotional intelligence (EI) of respondents and their workplace satisfaction. ${ }^{9}$

The project combined qualitative and quantitative research methods, using a questionnaire and interviews inviting participants to reflect on the causes of their levels of satisfaction at work, and the value and relevance of their legal education and training based on their subsequent experience as practising lawyers.

The research subjects were lawyers who were graduates of the School of Law at the University of Newcastle. They were considered an ideal cohort because their legal training at university included both standard undergraduate Bachelor of Laws (LLB) subjects and PLT in the Diploma of Legal Practice. The School of Law offers two streams: Option A, which involves the LLB, often combined with another degree; and Option B (the Professional Program) which, in addition to the combined degree, integrates the last two years of the

9 This project did not seek to prove causation. The aims did not include testing whether a certain type of education or training would produce a better or worse experience in legal practice, or whether it was the result of higher or lower scores in emotional intelligence or neuroticism. However, the researchers did look for correlations that might warrant further research, specifically on the effects that different types of education and training might have on the subsequent experience of lawyers in the workplace in the context of their emotional intelligence and intrinsic abilities to cope with stress. 
LLB with the Diploma of Legal Practice. The Professional Program is an accredited PLT program and involves at least 360 hours of legal placement, including 180 hours of supervised clinical legal education with real clients at the UNLC. Students who complete the Professional Program do not have to participate in PLT after graduation and, instead, are directly ready for admission to practice. Option A students do not participate in clinical legal education or legal placements and must arrange to complete their PLT at another institution after graduation.

Both qualitative and quantitative methods were used to achieve the research aims. These included a questionnaire and a semistructured interview protocol to encourage participants to reflect on the value and relevance of their legal education and training based on their subsequent experience as practising lawyers. The research instruments asked participants to describe their experiences in legal practice, to estimate their level of satisfaction at work and to identify their major sources of satisfaction and dissatisfaction. They were also asked to describe their earlier experiences in legal education and practical legal training, and to provide demographic indicators such as age, gender, years since admission, nature of practice, hours of practice and gross income. Other questions asked participants to respond using a seven-point Likert scale and short answers to indicate levels of satisfaction, stress, the demanding nature or their legal work, what they found most/least satisfying and most/least stressful, the quality of their professional support, and their future intentions regarding legal employment.

The questionnaire included an instrument to test 'neuroticism' as a measure of intrinsic stability of participants. Neuroticism is one of the 'Big 5' aspects in personality theory espoused originally in 1933 , and has been subjected to peer review frequently since then. ${ }^{10}$ In addition, the questionnaire included a short test for emotional intelligence, to test the assumption that lawyers with higher emotional intelligence would be better able to cope with stressful work conditions. ${ }^{11}$

${ }^{10}$ Lewis R Goldberg, 'A Broad-bandwidth, Public Domain, Personality Inventory Measuring the Lower-level Facets of Several Five-factor Models' in Ivan Mervielde, Ian Deary, Filip De Fruyt, and Fritz Ostendorf (eds), Personality Psychology in Europe (1999) vol 7, 7. Lewis R Goldberg, John A Johnson, Herbert W Eber, Robert Hogan, Michael C Ashton, C Robert Cloninger and Harrison G Gough, 'The International Personality Item Pool and the Future of Public-domain Personality Measures' (2006) 40 Journal of Research in Personality 84.

11 John D Mayer, Peter Salovey and David R Caruso, 'Emotional Intelligence: Theory, Findings, and Implications' (2004) 15 Psychological Inquiry 197; Chi-Sum Wong and Kenneth S Law, 'The Effects of Leader and Follower Emotional Intelligence on Performance and Attitude: An Exploratory Study' (2002) 13 The Leadership Quarterly 243; Len Tischler, Jerry Biberman and Robert McKeage, 'Linking Emotional Intelligence, Spirituality and Workplace Performance - Definitions, Models and Ideas for Research' 
The project was approved by the University of Newcastle Human Research Ethics Committee, which later accepted several variations following recommendations by a focus group. ${ }^{12}$

The researchers sent email invitations in the form of information letters to 326 graduates of the School of Law. The information letters had a link to the questionnaire which could be completed and submitted online in de-identified form. In addition, those wanting to contribute further, in a recorded interview, could indicate their consent by printing, signing and returning a consent form with relevant contact details.

Eighteen semi-structured telephone interviews were conducted according to the approved protocol, recorded, and transcribed in deidentified form.

\section{Findings}

Valid, completed questionnaires were received from 88 practising lawyers (27 per cent response) $)^{13}$ of whom 18 lawyers also agreed to a subsequent recorded interview. ${ }^{14}$ Participants had graduated from law school between 1997 and 2004 with a mean of 4.5 years in legal practice. Respondents to the questionnaire included 46 females and 40 males, aged from 25 to 56 years, with the majority ( 75 per cent) between 27 and 34 years. ${ }^{15}$ Most had completed their mandatory PLT through the integrated Professional Program at the University of Newcastle (78 per cent), compared with 22 per cent who had completed it elsewhere, such as the College of Law (16 per cent), The University of Technology, Sydney, or The Australian National University. The majority of respondents were employed solicitors in private firms (65 per cent) or community legal centres (3.4 per cent), followed by government lawyers (16 per cent), then 'associate' ( 9 per cent) and 'sole practitioner' $(4.5$ per cent).

(2002) 17 Journal of Managerial Psychology 203; Marjorie R Silver, 'Emotional Intelligence and Legal Education' (1999) 5 Psychology, Public Policy and Law, 1173.

12 The focus group of seven graduate lawyers recommended additional demographic questions, as well as: (1) Extending eligibility for graduates from the original 2000-2004 to 1997-2004; (2) Introducing a new telephone script for the research assistant for use in the recruitment process to check currency of email addresses and request contact details for graduates from third parties; (3) Amending the questionnaire to reduce the number of questions and simplify their format. The questionnaire would be offered via a web link rather than an attached email document; and (4) Amending the information statement, as well as questions on time-costing in legal practice and the extent of mentoring or other support provided by the employer or the Law Society.

13 This was a statistically relevant response rate, especially given a significant proportion of email addresses of alumni provided by the university were incorrect.

14 The researchers anticipated 100 completed questionnaires and 10 interviews; what the project lost in quantitative results it made up for in more qualitative data than expected. 
The participants were spread broadly across legal practice areas: 15 per cent in criminal law, 12 per cent in family law and the rest in administration, contract, commercial, debts, litigation, mining, environment, employment, construction, government, local government, liquor licensing, finance, mental health, mortgages, property, insurance, occupational health and safety, real estate, tax, wills, probate, victims compensation, workers compensation and workplace relations.

\section{A Income}

Participants were asked to approximate their annual salary as, anecdotally at least, high income could help compensate for highly demanding and/or stressful work. Salary ranges showed a significant variation from $\$ 20000$ - $\$ 30000$ (seven per cent, presumably parttime) to more than $\$ 160000$ (five per cent). The largest groups are represented in Graph 1.

\section{Graph 1: Percentage of Largest Groups by Income}

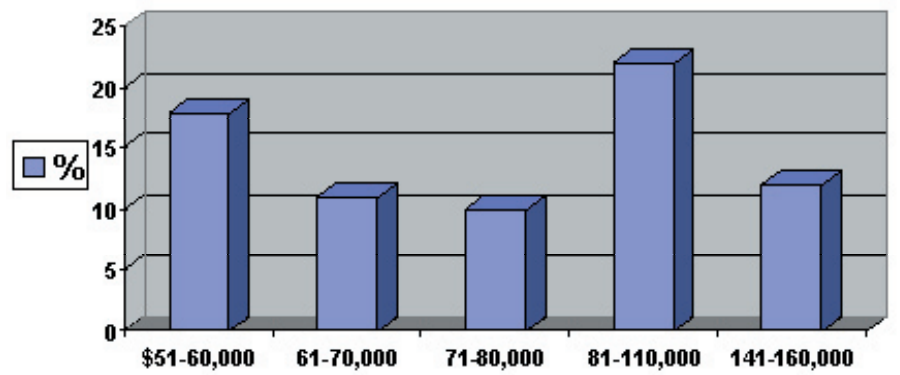

B Hours

Given the anecdotal view of lawyers spending long hours at work and the assumed connection with work-related stress, ${ }^{16}$ respondents were asked to say, on average, how many hours they worked per week. Unsurprisingly, the majority reported working long hours, as shown in Graph 2.

These findings are higher than other published research, specifically by the Law Society of New South Wales which reported an average of between 49 and 51 hours between 1999 and 2006. ${ }^{17}$

15 Two respondents did not state their gender. Aboriginal or Torres Strait Islanders and people with a disability were represented among the respondents, although the numbers in both groups were not statistically significant.

16 Patrick J Schiltz, 'On Being a Happy, Healthy, and Ethical Member of an Unhappy, Unhealthy and Unethical Profession' (1999) 52 Vanderbilt Law Review 871.

17 Urbis JHD Group, 2006 Profile of the Solicitors of New South Wales: Final Report (2007) <http://www.lawsociety.com.au/uploads/files/1183423066780 0.6275358533214839 . pdf $>$ at 7 December 2008. 


\section{Graph 2: Percentage of Average Hours at Work Per Week}

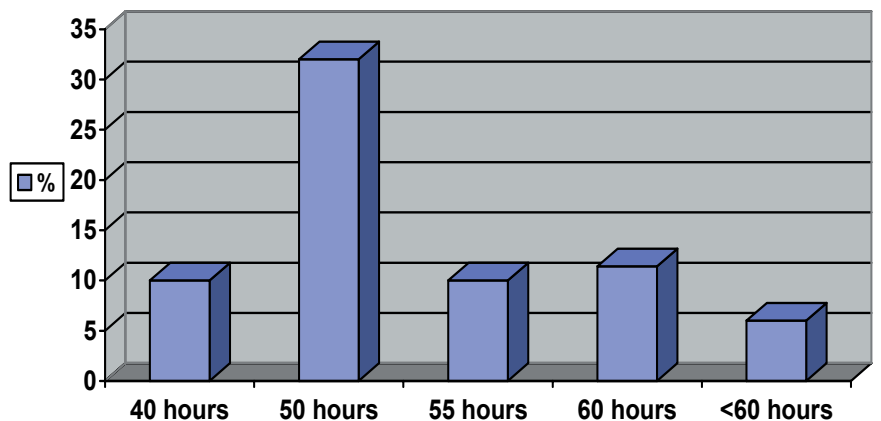

C Mobility

This study confirmed high mobility among graduate lawyers, consistent with earlier surveys, and may be symptomatic of dissatisfaction in the workplace. ${ }^{18}$ Over 61 per cent of respondents had been in their current job for two years or less. The mean number of positions since admission to practise law was 2.5 in 4.5 years, 72 per cent had changed employers at least once since admission, and 42 per cent had changed three or more times. ${ }^{19}$

Significantly, if given their time again, only half of the respondents would choose a career in law and only 30 per cent intended to remain in legal practice until retirement. Correlated with type of legal training, only 10.5 per cent of Option A graduates intended to continue with legal practice until retirement compared with 34.8 per cent of Option B graduates. Excerpts from the interviews, included below, help in understanding the main reasons behind the apparent insecurity and high mobility in the profession.

Despite the diversity of legal practice among respondents, 57 per cent claimed they would choose their current area of legal practice if given their time over again, while 40 per cent would choose another area of practice. In addition, 35 per cent claimed their current job had become significantly more stressful in the previous 12 months. These lawyers were significantly more likely to report low job satisfaction and intention to move on than those who simply reported ongoing levels of stress at work.

Correlating mobility results with PLT differences, Option A students were more 'stable', as 42 per cent were still in their first job and none had had more than three positions since admission. By contrast, only 25 per cent of Option B Professional Program students

18 Anonymous, 'Tom - One Lawyer's Story' (1990) 64 Law Institute Journal 1020; Victorian Women Lawyers Association, above n 8; Matthew Coghlan, above $n 8$.

19 Some Option A students would have been admitted several months after graduation due to PLT requirements; 4.5 years was the mean number of years since graduation. 
were still in their first job and 17 per cent had had three positions or more since admission. Reasons for this significant difference can only be speculated upon, but it is possible that Option B graduates, having had 'real life' experience with clients in a supervised legal practice, were less willing than Option A graduates to tolerate what they considered to be unreasonable working conditions. From their experiences of clinical legal education, Option B students may have had higher expectations in the quality of supervision and mentoring than many commercial firms provide.

\section{Workplace Conditions}

Many participants had changed jobs, or were considering a change, because of what they described as unreasonable billing pressure. Asked to consider their current position, 81 per cent of respondents claimed their work was 'highly demanding', not due to the nature of the work, but to high billing 'targets' and long hours.

I've worked in three different practices [since 2000] and it's been ... there's always been [billing] issues in the practice. ... that's definitely what I'd put as the biggest pressure: certainly the time recording and the budgets and expectations.

$[\mathrm{M}]$ aybe legal education has a role in telling people that at least once you're in for a few years, it's very easy to move around, but you shouldn't put up with [unreasonable billing pressure] and if you find yourself in that situation you should take steps to change it.

A large majority (67 per cent) also found their work 'very stressful' and, again, the reasons related mostly to billing pressure and long hours, and the culture perpetuating it.

I know a lot of people who are not very happy ... [inaudible] in their work. And I do think there has to be a change in culture in some firms.... it's affected a lot by the partner you work for.

[P] erhaps education of partners, I think, might be helpful.

I mean, that's nothing that the law school can tackle. ... it's really the culture of legal practices.

The next most common reason for changing firms was the apparent failure of senior lawyers to guide or supervise their juniors:

Lawyers, I find, are generally very bad teachers. ... it has been horrific to watch how some people just say 'Oh, go and do a reply brief' or 'Go and do this', and it's like, 'What the hell is that?'

One of the biggest things is getting positive feedback and just getting treated like you're on a similar level rather than being treated like an idiot.

While many claimed their levels of stress had increased significantly in the previous 12 months, several respondents 
commented on how much more stressful their previous position had been compared with their current one, suggesting that high stress forms a significant motivator for changing jobs.

Participants' comments show two opposing influences of increased legal experience on stress levels. More experience leads to promotion and seniority, involving more responsibility and higher stress. However, more experience can also lead to increased competence and confidence, enabling lawyers either to resist unreasonable demands by their employer or to resign and possibly 'change employers'.

Although this research did not aim to confirm it statistically, lawyers with lower rates of neuroticism and higher levels of emotional intelligence may have greater capacity to cope with, or refuse, unreasonable demands to work long hours to meet billing targets. Future research could look at factors that enable lawyers to make 'difficult' employment decisions, such as confronting partners who impose unreasonable billing targets which, in some cases, may be described as workplace bullying. ${ }^{20}$

\section{E Satisfaction and Performance}

Although high mobility among lawyers is a problem for law firms, it is not necessarily a problem for lawyers themselves, as satisfied lawyers may be less inclined to change jobs. As stated above, while most lawyers in this research found their employment to be highly demanding and very stressful, the stress they experienced was related to management issues and not necessarily to their legal work.

Is it possible for lawyers to experience both high stress levels in a highly demanding job, and still find satisfaction in that job? The results here show it is possible, although it was the experience of only a small majority. Around 57 per cent of respondents agreed their job satisfaction was high, despite a larger majority of 67 per cent saying their job was very stressful. One third of respondents agreed their job was both very stressful and very satisfying.

Similarly, although 81 per cent claimed their job was very demanding, 76 per cent believed they performed their job very well and, despite complaints about long hours and billing pressure, the same number claimed their supervisor agreed they performed their job very well. 


\section{F Continuing Legal Education (CLE) and Professional Support}

Given the long work hours, it is not surprising that 87 per cent of respondents had difficulty fitting in their CLE obligations. However, while most agreed they received excellent professional support at work, it was more common to get it from a colleague (74 per cent) than a supervisor (58 per cent) or a mentor (41 per cent).

Initially, the level of supervision was inadequate, and I don't think I realised how inadequate but I certainly do now. It made me feel quite unsure of myself for quite a while. I was mainly getting advice from the secretary.

Many lawyers appreciated their secretaries, with 45.5 per cent claiming they had excellent administrative support. Office quality also scored well with 65 per cent saying they had an excellent workspace.

Regarding external help, only 28.4 per cent of respondents agreed they received excellent professional support from professional groups such as law societies or associations, compared with 31 per cent who claimed they did not, and 35 per cent were uncommitted. Despite an apparently active Young Lawyers division of the Law Society of New South Wales, membership of the society has not been mandatory since 2002, and it is possible many graduate lawyers are not aware of the support it offers.

\section{G Emotional Intelligence and Neuroticism}

The research did not produce statistically relevant correlations between emotional intelligence and gender, age, stress levels or type of PLT. However there was a 'very relevant' correlation with satisfaction levels $(\mathrm{P}<.005)$, as lawyers who showed high emotional intelligence also reported higher levels of satisfaction at work.

Neuroticism scores were not significant alongside age, stress levels or type of CLE. However, gender was statistically relevant as women lawyers tended to show more indicators of neuroticism than men, and lawyers of both genders who showed significant neuroticism were significantly more likely to report high dissatisfaction at work $(\mathrm{P}<.008)$.

Most relevant was the correlation between these two measures alone. As indicated by Graph 3, lawyers with high scores in emotional intelligence were likely to show fewer indicators of neuroticism $(\mathrm{P}<.001)$. The line of best fit on Graph 3 confirms the statistical association between the two measures: emotional intelligence (E1 axis) tends to increase as neuroticism ( $\mathrm{Z}$ axis) decreases. 


\section{Graph 3: Scores of Neurotic Indicators Matched with Scores for Emotional Intelligence}

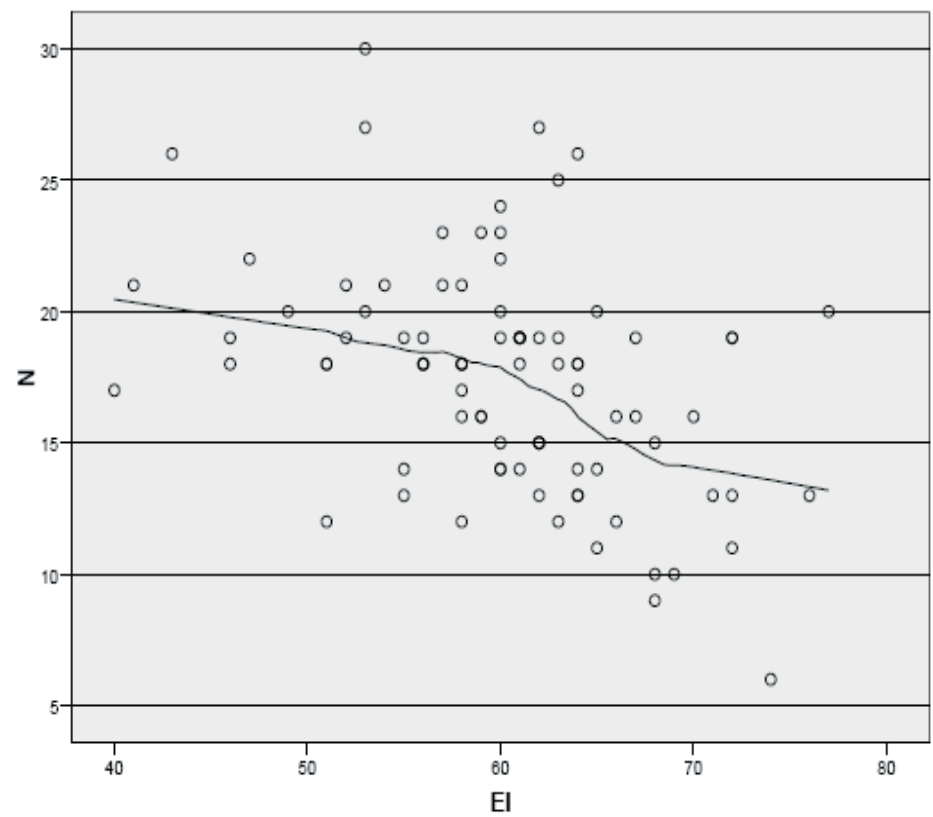

\section{H Practical Legal Training (PLT)}

Generally, most lawyers were satisfied with their practical legal education. Asked to respond to the statement 'My practical legal education was excellent in preparing me for legal practice', 57 per cent agreed compared to 12.5 per cent who disagreed. However, 70 per cent of the Option B Professional Program respondents who had participated in clinical legal education (Diploma of Legal Practice) integrated with LLB studies agreed that their practical legal education was excellent preparation for practice, while only 26 per cent of Option A respondents who had completed PLT subsequently, and without clinical legal education, agreed.

PLT programs usually include simulated exercises, simulated drafting and external placements. Participating lawyers who were Option A students at university were typically negative in reflecting on their PLT experiences.

[Regarding external placements] I didn't have the opportunity to do very much except observe, and it's really when you start working ... that's, I think, about developing more, feeling more confident and that sort of thing.

And I also thought that, on a variety of times ... [PLT provider] can be a very regrettable experience or, at the very least, not the best use of your time. 
I thought to myself, 'I cannot believe I'm paying thousands of dollars for this.' So it's not professional; it's simply just a lot of lawyers who are tutoring in areas I don't believe they necessarily have sufficient knowledge of.

Option B students, on the other hand, seemed to appreciate the clinical legal education experience, including real cases, real files and interaction with clients in a professional legal service environment with dedicated lawyer-supervisors.

The contact with clients is probably what I still say to this day is the most valuable thing that I've taken out of it. I was able to deal with clients straightaway after leaving Law School. I felt because I'd done it at Law School and that's the kind of thing that lets you hit the ground running $\ldots$

Just little things like interviewing clients for the first time and then ... now it comes as second nature, but when you first stated practising, even having an idea of what clients would be asking ... keeping them on track ... you probably don't realise was really helpful.

Typically, Option B participants were also positive about their clinical legal education with real-client, supervised practice being integrated with their law degree studies.

The course was great in that you were learning practical at the same time as you were learning the theoretical side ... So it often gave some concept as to why you were doing some things in lectures, when you had the practical classes.

I mean ... the [UNLC] professional program is really valuable. I think that it's great that it can be incorporated into the last couple of years ... the experience really did make it much easier for me to start - to start work. I felt like I wasn't going in blind, not knowing anything.

Simulated court exercises are common to both streams of PLT, however only Option B students felt moved to comment on them in the interviews. ${ }^{21}$

Also the advocacy course, like just being forced into those kinds of nervous or difficult situations when you've still got a safety net underneath and you're still allowed to make a mistake, but ... [inaudible] makes you feel like you have done it before even though it's your first time in a real courtroom. [I felt] so much more prepared when I got out.

I'm a naturally confident person, but I still, even to this day, get a little bit nervous in court ... My first few times in court [in the Professional Program] ... those bail applications, and I think it was a family law thing we did, certainly gave me some comfort that I'd actually been up on my feet, and probably there should be more of that, if anything, at law school.

21 The UNLC Professional Program includes cooperative participation from the Registrar of the District Court and judges from the Family Court of Australia, who hear students in moot interim lists and full trials. 
It gave me a hell of a lot of confidence, and one of the areas it was very good in doing was in [developing] the ability to stand up in a court situation and to deliver, you know, a plea or whatever.

\section{RECOMMENDATIONS}

The message from the participants in this study was that both law schools and PLT providers should ensure students are better informed about legal practice where it operates as a commercial business. Law schools adhere to conventions about teaching doctrinal law in the form of the 'Priestley 11,22 and PLT providers concentrate on the 'Competency Standards for Entry Level Lawyers'. ${ }^{23}$ It is possible that neither adequately prepares students for significant stressors that many experience in commercial legal practice. While law schools that provide clinical legal education offer students additional advantages arising from supervised experiences of working directly with clients, those programs fail to adequately address the realities of 'law-asbusiness' commercial firms that are the largest legal employer group in Australia.

This research confirms the validity of emotional intelligence and invites further research on the usefulness of courses for law students which are designed to improve self-awareness. The literature suggests that appropriate training may help individuals to cope with stressful situations, improve communication skills, and decide earlier in their training whether they are suited to legal practice and, if so, the kind of practice they should consider. ${ }^{24}$

22 The so-called 'Priestley 11' includes: civil procedure; evidence; professional conduct; criminal law and procedure; torts; contracts; property (real and personal); equity; administrative law; federal and state constitutional law; and company law. They derive from a 1992 meeting of the Consultative Committee of State and Territorial Admitting Authorities, headed by Justice Priestley of New South Wales, and were critiqued in Australian Law Reform Commission (ALRC), Managing Justice: A Review of the Federal Civil Justice System Report No $89(2000)<$ http://www.austlii.edu.au/au/other/alrc/ publications/reports/89/> at 7 December 2008.

23 Australasian Professional Legal Education Council, Law Admissions Consultative Committee, Competency Standards for Entry Level Lawyers (2002) <http://www.aplec.asn.au/Pdf/Competency_Standards_for_Entry_ Level_Lawyers.pdf $>$ at 7 December 2008.

24 Lawrence S Krieger, 'Human Nature As a New Guiding Philosophy for Legal Education and the Profession' (2008) 47 Washburn Law Journal 247; Emily Zimmerman, An Interdisciplinary Framework for Understanding and Cultivating Law Student Enthusiasm (2008) Drexel University College of Law Legal Studies Research Paper Series, 2008-W-02<http://papers. ssrn.com/sol3/papers.cfm?abstract_id=1186542> at 7 December 2008; David Chavkin, Experience is the Only Teacher: Meeting the Challenge of the Carnegie Foundation Report (2008) American University Washington College of Law Research Paper No 2008-16 <http://papers.ssrn.com/sol3/ papers.cfm?abstract_id $=1008960>$ at 7 December 2008. 
In addition, the respondents indicated relatively strong support for clinical legal education as preparation for their subsequent legal practice. This result was qualified by the apparent failure of both systems to adequately prepare students for aspects of commercial legal practice, and the risk of participant bias in giving a positive response.

\section{CONCLUSION}

This pilot project confirmed the high levels of stress among lawyers found by earlier research. However, it found that this high stress is likely related more to the conditions of employment than the nature of legal work itself. According to this research, most lawyers' stress is related to management issues, specifically high billing requirements, the associated long hours at work and the absence or poor quality of mentoring and supervision in the first few years of practice. Several respondents were definite in their interviews that the system of billing targets used in commercial legal practice was the cause of their dissatisfaction as a lawyer.

High stress among lawyers is not necessarily connected with low satisfaction. Most lawyers are satisfied at work, and a significant minority report both high stress and high satisfaction. Mobility of lawyers between firms is high, and likely due to either the ambition of some lawyers to progress professionally more than they see possible in their current firm, or the need to escape an oppressive regime of managerial practices, with inadequate supervision and support. In some cases, both may apply and employers aware of these issues should be able to respond appropriately and improve their retention rate of employed solicitors. The reported high levels of disinterest in continuing to practise should be a concern to all legal educators as well as employers, although the numbers actually leaving the profession may be less than those reporting an intention to do so.

The research also confirmed the relevance of a client-centred clinical legal education in a supervised legal practice, integrated simultaneously with legal studies towards the LLB. Future research should include broader and more qualitative studies on the relevance of conventional legal education and PLT to contemporary legal practice. It is possible a review of accredited PLT requirements and law school curricula will confirm the benefits of moving towards an integrated training model. It is also possible that changes have occurred in the attitudes and expectations of significant groups, including employer law firms, individual lawyers, law students and the general community. Of all the stakeholders, graduate lawyers appear to endure the worst consequences of the failure of our systems to adequately prepare people for the legal profession. However inertia in reform may increase secondary costs of instability in the profession, exacerbate the negative reputation of the profession, and 
make reform harder to instigate in the future. There may already be an obligation on law schools, at least morally, to inform students of the risks associated with the profession they are about to enter. Responsible programs will consider incorporating positive initiatives to prepare students not just for legal practice in an ideal world, but legal practice with competitive, commercial realities. 